\title{
The music-related quality of life: Italian validation of MuRQoL into MUSQUAV questionnaire and preliminary data from a cohort of postlingually deafened cochlear implant users
}

\author{
A. Frosolini ${ }^{1}$ (D) D. Parrino ${ }^{1}$ (D) $\cdot$ A. Mancuso $^{2}$ (D) $\cdot$ N. Coppola $^{2} \cdot$ E. Genovese $^{3} \cdot$ C. de Filippis ${ }^{1}$ (D)
}

Received: 5 November 2021 / Accepted: 3 January 2022 / Published online: 28 January 2022

(c) The Author(s) 2022

\begin{abstract}
Purpose Cochlear implant (CI) users do not receive much of the auditory information necessary for an accurate perception of music. This usually entails a dissatisfaction with the music they hear, so that their quality of life may potentially be affected. The main aim of this paper was to translate and validate into Italian an instrument to evaluate these aspects-The Music-Related Quality of Life Questionnaire (MuRQoL)— to help the work of clinicians and therapists.

Methods The translation of the MuRQoL into "Questionario Musica e Qualità della Vita" (MUSQUAV) was done according to the international guidelines. The translated questionnaire was administered to normal hearing $(\mathrm{NH})$ and $\mathrm{CI}$ users adults. Exploratory factor analysis, confirmatory factor analysis and known group method were used to confirm construct validity and applicability of MUSQUAV.

Results We retrieved 225 results. The MUSQUAV questionnaire was acceptable according to the goodness-of-fit indices. The correlation between the items, evaluated using Cronbach's $\alpha$ coefficient, indicates a good internal consistency $(>0.80)$. The non-parametric Mann-Whitney test showed significant differences in the distinct populations tested.

Conclusions The MUSQUAV questionnaire is a valid, low-cost and rapid instrument for professional workers in the audiological field, especially useful in the assessment of the patients' perception and musical engagement.
\end{abstract}

Keywords Music $\cdot$ Cochlear implant · Music therapy $\cdot$ Hearing loss · Questionnaire

A. Frosolini

andrea.frosolini@studenti.unipd.it

D. Parrino

daniela.parrino@gmail.com

A. Mancuso

antonio.mancuso@unimi.it

N. Coppola

Nicola.Coppola@cgm.com

E. Genovese

elisabetta.genovese@unimore.it

C. de Filippis

cosimo.defilippis@unipd.it

1 Department of Neuroscience DNS, University of Padova, Audiology Unit at Treviso Hospital, Piazzale Ospedale 1, 31100 Treviso, Italy

2 Department of Information Science, University of Milan, Milan, Italy

3 Audiology, Department of Diagnostic, Clinical and Public Health Medicine, University of Modena and Reggio Emilia, Modena, Italy

\section{Introduction}

\section{Strengths and limits of electric hearing}

Cochlear implants (CI) have definitely revolutionized the quality of life of people with profound hearing loss by restoring hearing functionality, improving their communication skills and social life [1].

Most CI users can benefit from a very good speech perception as their scores in pure tone audiometry and word recognition tests can result, in the best-case scenario, close to those of people with normal hearing. On the other hand, CI users do not spontaneously receive much of the temporal fine structure cues necessary for an accurate perception of pitch and timbre in music [2]. This usually entails dissatisfaction of the music they hear. This issue may potentially affect CI users' individual quality of life, considering the pervasive presence of music in daily life and its role in emotional expression, social and cultural connection [3]. 


\section{Relevance of music perception in $\mathrm{Cl}$ users}

Emerging music-focused CI technologies $[4,5]$ and auditory music training programs may improve several aspects of music perception and enjoyment [6]. For these reasons, evidence about the efficacy of music focused interventions are needed to enable patients and clinicians to make informed decisions about how much time and money they should invest.

A recent systematic review concluded that no single test has been adopted into widespread use, in a research or clinical context, to assess music experience after cochlear implantation [7]. Music outcomes in CI users have been measured with objective tests such as the MuSIC test, the Montreal battery of the evaluation of amusia, the Clinical Assessment of Music Perception and other instruments. However, they still are scarcely used, since the application of music perception tests requires specific instrumentation, professional expertise and more time than conventional audiometric tests. Above all, their scores do not necessarily correlate with patients' music appraisal, enjoyment, and participation in musical activities [8]. Consequently, questionnaires are relevant for evaluating the music perception and engagement in CI users.

With this aim, many questionnaires have been validated: the Munich Music Questionnaire (MUMU) [9], the University of Canterbury Music Listening Questionnaire (UCMLQ) [10], the Iowa Musical Background Questionnaire (IMBQ) [8] and the Music Related Quality of Life Questionnaire (MuRQoL) [3].

\section{Need for an Italian version of the music-related self-report assessment}

To the best of our knowledge, no Italian versions of subjective music assessment tools are available to date. In our opinion, among the above-mentioned questionnaires, the MuRQoL presents several advantages: (i) it is structured on a 5-point Likert scale, (ii) it involves both music perception and music engagement areas, (iii) it can be plotted in a matrix allowing the identification of specific areas to be improved through tailored musical training programs, and (iv) it is quite rapid to perform. A Turkish version has recently been validated as a helpful tool in the evaluation and rehabilitation of advanced sound perception in patients with electric hearing [11].

The main aim of this paper was to translate and validate an Italian version of the MuRQoL, to make it broadly available to clinicians and therapists. Two cohorts of normal hearing $(\mathrm{NH})$ adults were firstly administered the translated questionnaire: one of musicians/music students and the other one of people not necessarily involved in musical practices. Additionally, we evaluated the preliminary results from its application in a group of CI users, to direct future research in the field.

\section{Material and methods}

\section{Translation of the instrument}

The translation of the "Music related quality of life questionnaire" (MuRQoL) into an Italian version "Questionario Musica e Qualità della Vita" (MUSQUAV) was done according to the recent international guidelines of translation and cross-cultural validation of healthcare scales [12]. The questionnaire is made up of 2 mirror sections, each one containing 18 questions. The first section, called "frequency", analyzes how often the subject is able to perceive and be engaged in music whereas the second section, called "importance", examines how important it is for the subject to perceive and be engaged in music [3].

Firstly, two native Italian speakers, bilingual in English, independently translated the original questionnaire into Italian, with the permission of the author. In the second phase, a comparison was made of the two translated versions of the instrument and a synthesis was achieved with the consensus of the entire study group. In the third phase, a professional translator translated the obtained pooled version into English. The original questionnaire and back translation were compared with each other for coherence, and the initial MusQuaV version was then formulated for patient testing. The final phase of the translation process, the patient testing panel, was attended by five medical doctors and five CI users, patients of the audiological tertiary centers of the University Hospitals of Treviso. The participants (six female, four male) were native speakers of the Italian language. Every item of the initial Italian version was read aloud; at the same time, participants could follow the text on printed copies of the instrument. During the group discussion the patients were invited to answer two questions: "What does this statement mean to you?" and "Is there any other wording that would enable this meaning to be expressed more clearly?". Subsequent processing by the authors took the position of the testing panel into account and resulted in the elaboration of the Italian version of the MuRQoL, the MUSQUAV (Online Resource n1).

\section{Participants}

The study was conducted in accordance with the principles of the Helsinki Declaration [13]. Data were examined in 
compliance with Italian privacy and sensitive data laws, and with the in-house rules of our institution. Informed consent was obtained from each participant.

As previously reported, 160 subjects were necessary to perform cross-cultural validity study of a questionnaire consisting of 18 items [11]. Our normal hearing $(\mathrm{NH})$ validation sample consisted of amateur musician university students and amateur sport practitioners. We also report the preliminary data obtained on a cohort of CI patients of our department. Inclusion criteria were the following: (i) post-lingual deafness; (ii) unilateral/bilateral CI at least 18 months before questionnaire compilation; (iii) regular follow-up controls at the audiological tertiary centers of the University Hospital of Treviso. Demographic and clinical data (age, gender, etiology of deafness, years of CI use, CI model and audiological outcome) were recorded and are summarized in Table 1.

\section{Data collection}

The final version of MusQuaV was administered in most of the cases by directly inviting participants to fill in an online survey (Online Resource $\mathrm{n} 1$ ), and by manual compilation of the same survey for a subset of participants attending our clinic at Treviso Hospital. Data were collected from 18 May 2021 to 18 August 2021. Open questions regarding subjective hearing evaluation, precedent hearing pathologies and musical background were included in the survey and taken into account.

For the CI users group, audiometric test results at last evaluation (within 6 months before questionnaire submission) were considered. Audiometry was performed with Madsen Astera by GN Otometrics (Denmark), in accordance with european (IEC 60645-I) and ISO (389-1) standards, in a sound-attenuating room. We tested hearing thresholds without and with hearing devices, in the best aided condition, at frequencies from 250 to $8000 \mathrm{~Hz}$ and the mean Pure Tone Average (PTA2, threshold levels at 0.5, 1, 2, and $4 \mathrm{kHz}$ ) was then calculated. For speech audiometry, articulation gain curves were obtained using disyllabic, phonetically balanced words from an Italian wordlist for adults [Bocca]. The Speech Reception Threshold (SRT) - decibel level at which $50 \%$ of words could be repeated by the subject—was considered.

\section{Validity and reliability of the MUSQUAV questionnaire}

Only surveys filled out completely were taken into account for our analysis. Firstly, exploratory factor analysis (EFA) was performed for 18 frequency and 18 importance items separately, to find a factor based on the relationships between

Table 1 Demographic and general characteristics of participants

\begin{tabular}{|c|c|c|c|}
\hline & $\begin{array}{l}\text { Student of } \\
\text { music-infor- } \\
\text { matics }\end{array}$ & Amateur sport practitioners & CI patients \\
\hline Number of participants & 88 & 97 & 35 (44 CIs) \\
\hline Average age (years) & $33.10 \pm 17.25$ & $34.56 \pm 10.49$ & $60.31 \pm 17.01$ \\
\hline Sex: female; male; non-binary & $34 ; 52 ; 2$ & $61 ; 36$ & $21 ; 14$ \\
\hline Mean subjective evaluation of hearing* & $8.95 \pm 1.04$ & $9.01 \pm 1.48$ & $6.23 \pm 1.97$ \\
\hline Musical studies & $66 / 88(75 \%)$ & $27 / 97(27.83 \%)$ & $2 / 35(5.71 \%)$ \\
\hline Professional musician & $15 / 88(17.04 \%)$ & $1 / 97(1.03 \%)$ & $0 / 35$ \\
\hline Etiology of hearing loss & NA & NA & $\begin{array}{l}\text { Unknown (16); MD (5); Otosclerosis (4); Chronic } \\
\text { otitis (4); AIED (3); Meningitis (2) }\end{array}$ \\
\hline Hearing rehabilitation modality & NA & NA & Unilateral (7 Right, 6 Left); Bimodal (13); Bilateral (9) \\
\hline Average years of CI use ${ }^{* *}$ & NA & NA & $6.25 \pm 6.01$ \\
\hline CI model & NA & NA & Medel (20); Cochlear (13); Oticon (9); AB (2) \\
\hline PTA2 unaided: Right; Left (dB) & NA & NA & $104.53 \pm 24.97 ; 105 \pm 24.24$ \\
\hline PTA2 with CI: Right; Left (dB) & NA & NA & $37 \pm 14.04 ; 37.5 \pm 16.09$ \\
\hline $50 \%$ SRT with CI: Right; Left (dB) & NA & NA & $46.19 \pm 12.71 ; 44.96 \pm 9.49$ \\
\hline
\end{tabular}

AIED Autoimmune Inner Ear Disease, CI Cochlear Implant, MD Meniere's Disease, NA Not Applicable, PTA2 Pure Tone Average at 500-10002000-4000 Hz, SRT Speech Recognition Threshold

*In visual-analog scale from 0 to 10

**Considered from the date of first $\mathrm{CI}$ in bilateral users 
the variables. Principal axis factoring extraction method and 'oblimin' rotation were used [14]. Kaiser-Meyer-Olkin (KMO) and Bartlett's test of sphericity were used to test the significance of factor structures. A KMO value close to one indicates sampling adequacy whereas the item must be removed if a factor load is below 0.30; a Bartlett test value $\mathrm{p}<0.05$ confirms sampling adequacy [15].

The construct validity of the questionnaire was measured through Confirmatory Factor Analysis (CFA) and the 'known group' method. Independent evaluation criteria, known as goodness-of-fit indices, were used to evaluate the results of the CFA. The fit of the model was determined using the root mean square error of approximation (RMSEA), as previously reported [11].

It was aimed to use the known-group method to evaluate the construct validity of the questionnaire and its ability to detect differences by comparing the scores of normal hearing music players, normal hearing sport players and postlingual deaf CI users. It can be stated that a scale is valid if it gives significantly different scores for groups that are known to be apart from one another in a specific concept. The non-parametric Mann-Whitney test was used to verify this hypothesis, a $p$ value $<0.05$ was considered significant.

The open source software jamovi version 1.6, the SPSS Version 25.0 and $\mathrm{R}$ core team version 4.0 were used for our statistical purposes [16, 17].

\section{Results}

Our normal hearing $(\mathrm{NH})$ validation sample consisted of 88 amateur musician university students with an average age of $33.10 \pm 17.25$ years and 97 amateur sport practitioners with an average age of $34.56 \pm 10.49$ years. Other demographic and general data are summarized in Table 1.

The MUSQUAV questionnaire was acceptable according to the goodness-of-fit indices obtained as a result of the CFA for both scales. As shown in Table 2, root mean square error of approximation (RMSEA) and standardized root mean square residual (SRMR) resulted within normal limits: SRMR 0.0758 for Frequency and SRMR 0.0683 for Importance $(0.05 \leq \mathrm{SRMR} \leq 0.10$ indicate acceptable fit $)$ and RMSEA 0.0842 for Frequency and 0.104 for importance $(0.05 \leq$ RMSEA $\leq 0.10$ indicate acceptable fit) [18].

Two factors (called factor 1 and factor 2) for 'Frequency Scale' and for 'Importance Scale' were extracted based on the first two eigenvalues and scree plots, as shown in Fig. 1a and $b$. As in the original questionnaire, factor 1 was interpreted as 'music perception' and factor 2 as 'music engagement' in both scales. Results obtained from EFA are presented in Table 3 third, fourth and fifth columns). As each item on a factor had a loading, it was determined that the 18 items in the MUSQUAV-frequency scale and 18 in the MUSQUAV-importance scale provided structural validity. In the case of importance, we preferred to keep questions 17 and 18 in the involvement factor to maintain consistency between the 2 groups of 18 questions. The dimensions obtained were structurally significant according to the results of the Bartlett test (by frequency scale: $\mathrm{X} 2=1058$, $p<0.001$; by scale of importance: $\mathrm{X} 2=1714, \mathrm{p}<0.001$ ). The $p$ value $<0.005$ confirms that the variances of the two factors (perception and engagement) are different.

The two factors chosen in the exploratory analysis account for $36 \%$ cumulative frequency of the variance (factor $123.1 \%$ and factor $212.9 \%$ ) and for importance cumulatively $48.9 \%$ (factor $136,7 \%$ and factor $212.1 \%$ ).
Table 2 CFA Goodness-of-fit indices of the Italian version of the music-related quality of life questionnaire $(N=171)$

\begin{tabular}{lllll}
\hline & & & \multicolumn{2}{l}{ Italian } \\
\cline { 4 - 5 } Fit indices & Good fit & Acceptable fit & Frequency scale & Importance scale \\
\hline$N$ & - & - & 171 & 171 \\
$\mathrm{df}$ & - & - & 134 & 134 \\
$\chi^{2}$ & $0 \leq \chi 2 \leq 2 \mathrm{df}$ & $2 \mathrm{df} \leq \chi 2 \leq 3 \mathrm{df}$ & 296 & 384 \\
$\mathrm{p}$ & $0.05 \leq P \leq 1.00$ & $0.001 \leq P \leq 0.05$ & $<0.001$ & $<0.001$ \\
$\chi 2 / \mathrm{df}$ & $0 \leq \chi 2 / \mathrm{df} \leq 2$ & $2 \leq \chi 2 / \mathrm{df} \leq 3$ & 2.209 & 2.866 \\
SRMR & $0.00 \leq \mathrm{SRMR} \leq 0.05$ & $0.05 \leq \mathrm{SRMR} \leq 0.10$ & 0.0758 & 0.0683 \\
RMSEA & $0.00 \leq \mathrm{RMSEA} \leq 0.05$ & $0.05 \leq \mathrm{RMSEA} \leq 0.10$ & 0.0842 & 0.104 \\
CFI & $0.95 \leq \mathrm{CFI} \leq 1.00$ & $0.90 \leq \mathrm{CFI} \leq 0.95$ & 0.83 & 0.848 \\
TLI & $0.95 \leq \mathrm{TLI} \leq 1.00$ & $0.90 \leq \mathrm{TLI} \leq 0.95$ & 0.806 & 0.827 \\
\hline
\end{tabular}

CFI comparative fit index, RMSEA root mean square error of approximation, SRMR standardized root mean square residual, TLI Tucker-Lewis index 
Fig. 1 a, b Scree plots of exploratory factor analysis on the 'Frequency scale' and on the 'Importance scale' of MUSQUAV

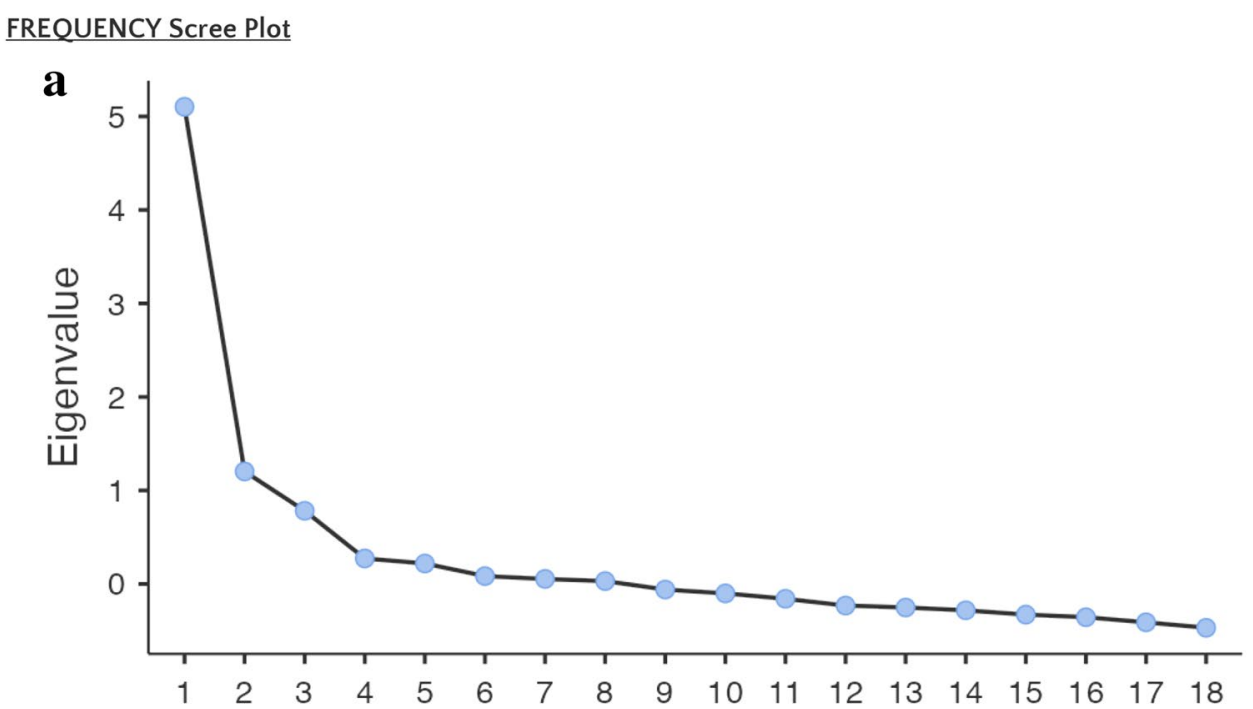

Factor

IMPORTANCE Scree Plot

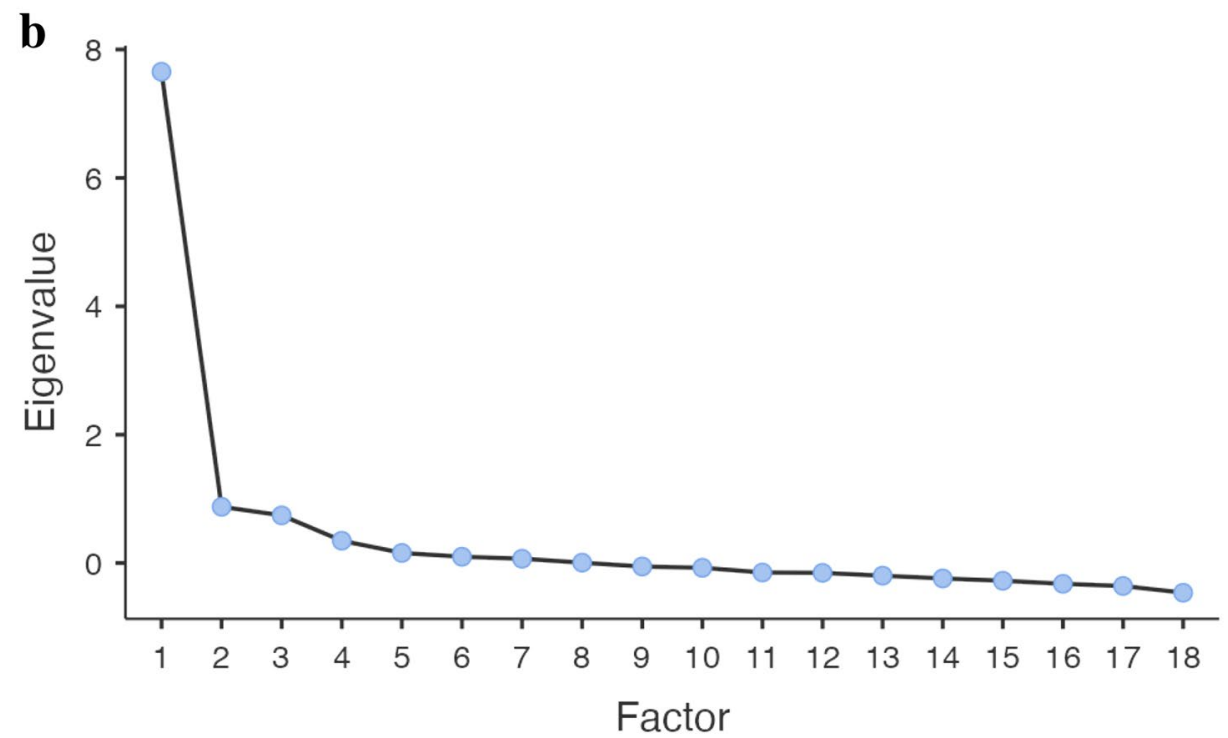

Table 2 shows the CFA values compared with the reference values.

The correlation between the items of the questionnaire evaluated using Cronbach's $\alpha$ coefficient, reported 0.848 for frequency scale and 0.925 for importance scale, indicating a good internal consistency for both scales. $(>0.80)$, The estimated Cronbach's $\alpha$ coefficients for correlation between the items of each subscale were 0.851 (music perception subscale) and 0.737 (music engagement subscale) $(0.6<\alpha<0.8$ indicate acceptable validity) for frequency scale and 0.911 (music perception subscale) and 0.838 (music engagement subscale) for importance scale.
The cohort of CI patients consisted of 20 females and 15 males with an average age of 60.31 years (standard deviation \pm 17.01$)$. The non parametric Mann-Whitney test showed significant differences in the results of importance and frequency scales of MUSQUAV in the three populations tested. These data, summarized in Table 4 further confirmed the reliability of the questionnaire in identifying differences based on musical experience of participants, with higher values of frequency for the normal hearing group compared with the cochlear implant group and similar values of importance in the different groups, as previously reported [3]. 
Table 3 KMO measure of sampling adequacy and exploratory factor analysis for the two sessions of the MUSQUAV questionnaire

Frequency session of the MUSQUAV

Overall

1. Riesci a distinguere diversi ritmi musicali?

2. Riesci a seguire una melodia (ad esempio la melodia di una canzone o di un motivo familiare)?

3. Riesci a sentire le differenze di dinamica (cioè se la musica è ad alto o a basso volume)?

4. Riesci a riconoscere le parole nelle canzoni?

5. Riesci a distinguere il suono dei diversi strumenti musicali (violino, pianoforte, sassofono, chitarra...)?

6. Riesci a percepire il significato della musica (cioè l'emozione, perché è stata creata, quale messaggio vuole comunicare)

7. Riesci a sentire la musica senza bisogno di sforzarti, senza doverti concentrare?

8. Riesci a riconoscere una musica che ti è familiare (ad esempio una canzone, un cantante o una melodia)?

9. Sai giudicare la qualità di una performance musicale (ad esempio il cantato o la parte strumentale)?

10. Pensi di udire la musica come tutti gli altri?

11. Percepisci come intonata la musica che ascolti?

12. Ti piace la musica in ambienti rumorosi (ad esempio ad una festa, al ristorante o in auto) in assenza di stimoli visivi? performance anche visivamente?

14. Metti la musica in sottofondo mentre fai qualcos'altro (ad es. durante la lettura, la pittura, il giardinaggio, i lavori domestici, l'esercizio o semplicemente il relax)?

15. Ascolti musica mentre viaggi (ad esempio in auto)?

16. Ascolti musica nuova, che non hai mai sentito prima?

17. Partecipi a eventi musicali (ad esempio musical, concerti o festival musicali)?

18. Canti, suoni uno strumento musicale o fischietti quando sei da solo?

Importance session of the MUSQUAV
KMO Factor 1 Factor 2 Uniqueness MSA

$\begin{array}{llll}0.859 & \text { NA } & \text { NA } & \text { NA } \\ 0.902 & 0.571 & - & 0.527 \\ 0.894 & 0.662 & - & 0.406 \\ 0.899 & 0.715 & - & 0.528 \\ 0.831 & 0.595 & - & 0.699 \\ 0.912 & 0.565 & - & 0.554 \\ & & & \\ 0.888 & 0.404 & - & 0.701 \\ & & & \\ 0.882 & 0.770 & - & 0.434 \\ 0.897 & 0.664 & - & 0.577 \\ & & & \\ 0.813 & 0.423 & - & 0.660 \\ 0.559 & 0.387 & 0.349 & 0.847 \\ 0.889 & 0.625 & - & 0.647 \\ 0.730 & - & 0.459 & 0.817 \\ & & & \\ 0.774 & - & 0.579 & 0.677\end{array}$

$0.579 \quad 0.677$

$0.423 \quad 0.798$

0.779

$\begin{array}{llll}0.781 & - & 0.302 & 0.771\end{array}$

$\begin{array}{llll}0.854 & - & 0.540 & 0.588\end{array}$

$\begin{array}{llll}0.842 & - & 0.546 & 0.717\end{array}$

$\begin{array}{llll}0.916 & - & 0.606 & 0.568\end{array}$

KMO Factor 1 Factor 2 Uniqueness MSA

Overall

0.908

NA

NA

NA

1. Quanto è importante per te riuscire a distinguere diversi ritmi musicali?

0.906

0.836

$-$

0.318

2. Quanto è importante per te riuscire a seguire una melodia (ad esempio la melodia di una canzone o di un motivo familiare)?

3. Quanto è importante per te riuscire a sentire le differenze di dinamica (cioè se la musica è ad alto o a basso volume)?

4. Quanto è importante per te riuscire a riconoscere le parole nelle canzoni?

$0.916 \quad 0.859$

$-$

$0.943 \quad 0.783$

$-$

0.405

5. Quanto è importante per te distinguere il suono dei diversi strumenti musicali (violino, pianoforte, sassofono, chitarra...)?

6. Quanto è importante per te riuscire a percepire il significato della musica (cioè l'emozione, perché è stata creata, quale messaggio vuole comunicare)

7. Quanto è importante per te riuscire a sentire la musica senza bisogno di sforzarti, senza doverti concentrare?

8. Quanto è importante per te riuscire a riconoscere una musica che ti è familiare (ad esempio una canzone, un cantante o una melodia)?

9. Quanto è importante per te riuscire a giudicare la qualità di una performance musicale (ad esempio il cantato o la parte strumentale)?

10. Quanto è importante per te la consapevolezza di udire la musica come tutti gli altri?

$\begin{array}{llll}0.874 & 0.595 \quad-\quad 0.627\end{array}$

$\begin{array}{lllll}0.933 & 0.861 & - & 0.341\end{array}$

$\begin{array}{llll}0.900 & 0.577 \quad-\quad & 0.565\end{array}$

$\begin{array}{llll}0.897 & 0.562 & - & 0.603\end{array}$

$\begin{array}{llll}0.911 & 0.614 & - & 0.553\end{array}$

$\begin{array}{llll}0.934 & 0.778 & - & 0.421\end{array}$

$\begin{array}{llll}0.837 & 0.397 & - & 0.808\end{array}$

11. Quanto è importante per te percepire come intonata la musica che ascolti (armonica, melodiosa)?

0.936

0.676

$-$

0.545

12. Quanto è importante per te apprezzare la musica in ambienti rumorosi (ad esempio ad una festa, al

0.9110 .381

0.319

0.636

ristorante o in macchina) in assenza di stimoli visivi?

13. Quanto è importante per te ascoltare musica su TV, DVD, smartphone o sul computer quando è

$0.905 \quad 0.366$

0.411

0.551 possibile seguire la performance anche visivamente? 
Table 3 (continued)

\begin{tabular}{|c|c|c|c|c|}
\hline Importance session of the MUSQUAV & $\begin{array}{l}\text { KMO } \\
\text { MSA }\end{array}$ & Factor 1 & Factor 2 & Uniqueness \\
\hline $\begin{array}{l}\text { 14. Quanto è importante per te avere musica in sottofondo mentre fai qualcos'altro (ad esempio } \\
\text { durante la lettura, la pittura, il giardinaggio, i lavori domestici, l'esercizio o semplicemente il relax)? }\end{array}$ & 0.806 & - & 0.811 & 0.403 \\
\hline 15. Quanto è importante per te ascoltare musica mentre viaggi (ad esempio in auto)? & 0.844 & - & 0.717 & 0.435 \\
\hline 16. Quanto è importante per te ascoltare musica nuova, che non hai mai sentito prima? & 0.907 & 0.353 & 0.401 & 0.577 \\
\hline $\begin{array}{l}\text { 17. Quanto è importante per te partecipare a eventi musicali (ad esempio musical, concerti o festival } \\
\text { musicali)? }\end{array}$ & 0.918 & 0.418 & 0.283 & 0.630 \\
\hline $\begin{array}{l}\text { 18. Quanto è importante per te cantare, suonare uno strumento musicale o fischiettare quando sei da } \\
\text { solo? }\end{array}$ & 0.944 & 0.526 & 0.286 & 0.497 \\
\hline
\end{tabular}

KMO Kaiser-Meyer-Olkin, MSA Measure of Sample Adequacy, NA Not Applicable

'Principal axis factoring' extraction method was used in combination with a 'oblimin' rotation. Factor 1 corresponds to "Percezione" (Perception) and Factor 2 correspond to "Coinvolgimento" (Engagement) (Dritsakis et al. [3])

Multiple regressions were performed for the NH subjects (Table 5). As regards the importance, being a musician and having done musical studies are significant: the average value of importance decreases by 0.4 passing from musicians to non-musicians and increases by 0.4 with musical studies. Also for frequency, passing from musician to non-musician is significant (the average of the frequencies decreases by 0.17 ), and also the average decreases with the increasing age of participants $(0.23$ for each year).

Figure 2 shows the combinations of frequency and importance scores following the classification proposed by Dristakis et al. [3]. This matrix visualization well synthesized the differences between the NH and CI populations. As can be seen the CIs are positioned in the top-left quadrant, with great importance and low frequency, and therefore with a highly critical impact from the perspective of rehabilitation.

\section{Discussion}

Perception of music is a complex auditory and cognitive activity that can be especially challenging for patients with hearing loss [2]. The consequence of poor music engagement and participation can affect patients' Quality of Life (QoL). To the best of our knowledge, no evaluation instruments are available to assess the musical attitude of Italian patients with hearing loss [7]. This evidence has led us to the translation and validation of MuRQoL into this Italian version, the MUSQUAV.
The MurQoL was developed in 2017 by Dritsakis et al. with the contributions of a wide and qualified group of researchers in the field of audiology and with the direct participation of CI patients. The final version was validated on a cohort of 147 CI users and 68 normal hearing matched controls. The study resulted with high reliability of the questionnaire, for the test-retest reliability and the value of Cronbach's $\alpha$ that exceeded 0.90 . Moreover, the ability of the MuRQoL questionnaire to predict aspects of QoL was shown by the positive correlation between MuRQoL frequency engagement and the SF12v2-RP domain, which covers activity limitations as a result of physical health. A subsequent validation in the Turkish language, on $161 \mathrm{CI}$ users and 162 normal hearing controls, confirmed previous findings regarding reliability and validity of the questionnaire [11].

Our findings on 180 normal hearing controls and $35 \mathrm{CI}$ patients are in line with the data previously reported by Dritsakis and Akbulut. This indicates cross-cultural validity of the MuRQoL questionnaire and validity and reliability of the Italian MUSQUAV. Moreover, our preliminary findings on CIs showed a great need for musical interventions for these patients (Fig. 2) and consequent possible impact on their quality of life.

The MUSQUAV questionnaire can be used as a screening tool to identify individual rehabilitation needs in a clinic, using the matrix diagram (available in the Online Resource $\mathrm{n} 2$ ). At a population level, the MUSQUAV can be used as a reliable and valid outcome measure for the evaluation of music-focused interventions on hearing impaired patients. A decision tree and score calculator, to aid researchers and 
Table 4 The non-parametric Mann-Whitney test showed significant differences in the results of importance and frequency scales of MUSQUAV in the three populations tested: NH Amateur Musicians vs
NH Sport practitioner; NH vs CI, NH Amateur Musicians vs CI, NH Amateur Musician vs NH Sport practitioner

\begin{tabular}{|c|c|c|c|c|c|c|}
\hline \multirow[b]{2}{*}{ Measure } & \multicolumn{2}{|l|}{ CI } & \multicolumn{2}{|l|}{$\mathrm{NH}$} & \multicolumn{2}{|c|}{ Mann-Whithney } \\
\hline & Median & Range & Median & Range & $U$ & $P$ \\
\hline Frequency & 2.42 & $1.50-4.44$ & 4.17 & $1.44-5.00$ & 534 & $<0.001$ \\
\hline Importance & 3.28 & $1.67-4.94$ & 3.89 & $1.06-5.00$ & 1516.5 & 0.002 \\
\hline Frequency Perception & 2.86 & $1.64-4.73$ & 4.36 & $1.18-5.00$ & 556.5 & $<0.001$ \\
\hline Importance Perception & 3.36 & $1.73-4.91$ & 4.00 & $1.09-5.00$ & 1639.5 & 0.008 \\
\hline Frequency Engagement & 2.14 & $1.00-4.14$ & 3.71 & $1.86-5.00$ & 650.5 & $<0.001$ \\
\hline \multirow[t]{2}{*}{ Importance Engagement } & 3.00 & $1.14-5.00$ & 3.71 & $1.00-5.00$ & 1490 & 0.001 \\
\hline & \multicolumn{2}{|l|}{ CI } & \multicolumn{2}{|c|}{ NH-Mus } & \multicolumn{2}{|c|}{ Mann-Whithney } \\
\hline Measure & Median & Range & Median & Range & $U$ & $P$ \\
\hline Frequency & 2.42 & $1.50-4.44$ & 4.28 & $1.44-5.00$ & 217 & $<0.001$ \\
\hline Importance & 3.28 & $1.67-4.94$ & 4.00 & $2.50-5.00$ & 518 & $<0.001$ \\
\hline Frequency Perception & 2.86 & $1.64-4.73$ & 4.36 & $1.18-5.00$ & 250.5 & $<0.001$ \\
\hline Importance Perception & 3.36 & $1.73-4.91$ & 4.00 & $2.45-5.00$ & 620 & $<0.001$ \\
\hline Frequency Engagement & 2.14 & $1.00-4.14$ & 4.14 & $1.86-5.00$ & 234.5 & $<0.001$ \\
\hline \multirow[t]{2}{*}{ Importance Engagement } & 3.00 & $1.14-5.00$ & 4.00 & $1.86-5.00$ & 516.5 & $<0.001$ \\
\hline & \multicolumn{2}{|l|}{ CI } & \multicolumn{2}{|c|}{ NH-Sport } & \multicolumn{2}{|c|}{ Mann-Whithney } \\
\hline Measure & Median & Range & Median & Range & $U$ & $P$ \\
\hline Frequency & 2.42 & $1.50-4.44$ & 3.94 & $2.61-4.83$ & 317 & $<0.001$ \\
\hline Importance & 3.28 & $1.67-4.94$ & 3.58 & $1.06-5.00$ & 998.5 & 0.132 \\
\hline Frequency Perception & 2.86 & $1.64-4.73$ & 4.23 & $2.36-5.00$ & 306 & $<0.001$ \\
\hline Importance Perception & 3.36 & $1.73-4.91$ & 3.64 & $1.09-5.00$ & 1019.5 & 0.17 \\
\hline Frequency Engagement & 2.14 & $1.00-4.14$ & 3.57 & $2.71-4.71$ & 416 & $<0.001$ \\
\hline \multirow[t]{2}{*}{ Importance Engagement } & 3.00 & $1.14-5.00$ & 3.21 & $1.00-5.00$ & 973 & 0.095 \\
\hline & \multicolumn{2}{|l|}{ NH-Mus } & \multicolumn{2}{|c|}{ NH-Sport } & \multicolumn{2}{|c|}{ Mann-Whithney } \\
\hline Measure & Median & Range & Median & Range & $U$ & $P$ \\
\hline Frequency & 4.28 & $1.44-5.00$ & 3.94 & $2.61-4.83$ & 2390 & $<0.001$ \\
\hline Importance & 4.00 & $2.50-5.00$ & 3.58 & $1.06-5.00$ & 2235.5 & $<0.001$ \\
\hline Frequency Perception & 4.36 & $1.18-5.00$ & 4.23 & $2.36-5.00$ & 3048.5 & 0.0614 \\
\hline Importance Perception & 4.00 & $2.45-5.00$ & 3.64 & $1.09-5.00$ & 2518 & $<0.001$ \\
\hline Frequency Engagement & 4.14 & $1.86-5.00$ & 3.57 & $2.71-4.71$ & 2291.5 & $<0.001$ \\
\hline Importance Engagement & 4.00 & $1.86-5.00$ & 3.21 & $1.00-5.00$ & 2210 & $<0.001$ \\
\hline
\end{tabular}

CI Cochlear Implant, $\mathrm{NH}$ Normal Hearing group, Mus Amateur Musician

clinicians in the use of the MUSQUAV, is available in the Online Resource n3 [3].

Future longitudinal studies should assess the ability of the MUSQUAV to detect clinical changes in patients who underwent music focused intervention, including possible correlations with language and communication abilities, which have recently been debated $[19,20]$. The extension of music evaluation (including MUSQUAV questionnaire) and music focused interventions on people with mild hearing loss should also be considered, given the fact that hearing aids (HA) and CI share similar technologies-implication of bimodal hearingand patients often pass from hearing aids to CI during their lifetime due to the natural course of hearing loss diseases.

In conclusion, the present MUSQUAV questionnaireItalian version of MuRQoL-is a valid, low-cost and rapid instrument available for professional workers in the audiology field to assess perception and musical engagement of patients. 
Table 5 Results of multiple regression for the normal hearing group of participants

\begin{tabular}{|c|c|c|c|}
\hline \multicolumn{4}{|l|}{ Frequency } \\
\hline \multirow[b]{2}{*}{ Model } & Unstandardized coefficient & Standardized coefficient & $p$ \\
\hline & $B$ & \multicolumn{2}{|l|}{ Beta } \\
\hline (Constant) & 3.972 & - & $<0.05$ \\
\hline Group (amateur musician—sport practitioners) & -0.423 & -0.3 & $<0.05$ \\
\hline Gender & 0.135 & 0.095 & 0.222 \\
\hline Age & -0.005 & -0.092 & 0.232 \\
\hline Subjective hearing evaluation & 0.039 & 0.014 & 0.847 \\
\hline Musical studies & 0.21 & 0.149 & 0.071 \\
\hline Professional musicians & -0.003 & -0.001 & 0.987 \\
\hline \multicolumn{4}{|l|}{ Importance } \\
\hline & Unstandardized coefficient & Standardized coefficient & $p$ \\
\hline Model & $B$ & \multicolumn{2}{|l|}{ Beta } \\
\hline (Constant) & 4.343 & - & $<0.05$ \\
\hline Group (amateur musician—sport practitioners) & -0.163 & -0.178 & 0.029 \\
\hline Gender & 0.085 & 0.092 & 0.235 \\
\hline Age & -0.008 & -0.238 & 0.002 \\
\hline Subjective Hearing evaluation & 0.09 & 0.05 & 0.491 \\
\hline Musical studies & 0.113 & 0.123 & 0.133 \\
\hline Professional musicians & 0.193 & 0.123 & 0.108 \\
\hline
\end{tabular}
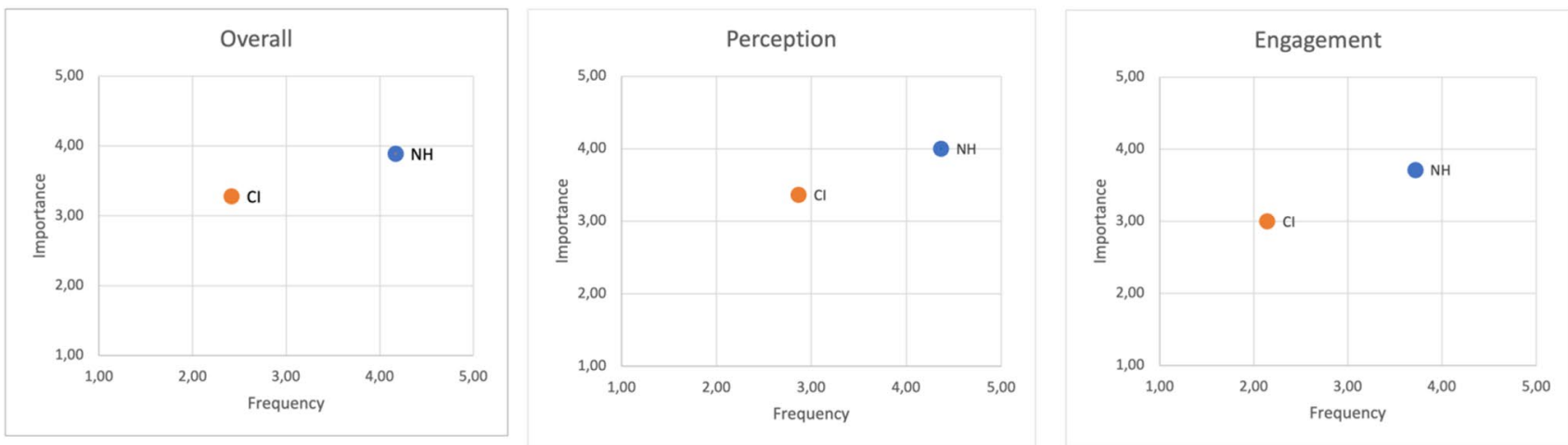

Fig. 2 Matrix of frequency and importance for $\mathrm{CI}$ and $\mathrm{NH}$ : overall, perception and engagement

Supplementary Information The online version contains supplementary material available at https://doi.org/10.1007/ s00405-022-07258-1.

Acknowledgements The authors thank Ms. Alison Garside and Mrs. Carla Baldini for direct and back translation of the questionnaire and for correcting the English version of this paper. The authors also thank Dr. Giorgos Dritsakis and Dr. Daniele Borsetto for their priceless help and guidance.

Author contributions AF: conceptualization; data curation; methodology; investigation; formal analysis; original draft; writing, review \& editing. DP: data curation; original draft; methodology; investigation; writing, review \& editing. AM: data curation; formal analysis; methodology; investigation; writing, review \& editing. NC: data curation; formal analysis; review \& editing. EG: supervision. CdF: review \& editing; supervision.

Funding This research received no specific grant from any funding agency in the public, commercial, or not-for-profit sectors.

Data availability The data that support the findings of this study are available from the corresponding author $(\mathrm{AF})$, upon reasonable request.

\section{Declarations}

Conflict of interest The authors have no conflicts of interest to disclose. 
Open Access This article is licensed under a Creative Commons Attribution 4.0 International License, which permits use, sharing, adaptation, distribution and reproduction in any medium or format, as long as you give appropriate credit to the original author(s) and the source, provide a link to the Creative Commons licence, and indicate if changes were made. The images or other third party material in this article are included in the article's Creative Commons licence, unless indicated otherwise in a credit line to the material. If material is not included in the article's Creative Commons licence and your intended use is not permitted by statutory regulation or exceeds the permitted use, you will need to obtain permission directly from the copyright holder. To view a copy of this licence, visit http://creativecommons.org/licenses/by/4.0/.

\section{References}

1. Messersmith JJ, Entwisle L, Warren S, Scott M (2019) Clinical practice guidelines: cochlear implants. J Am Acad Audiol 30(10):827-844. https://doi.org/10.3766/jaaa.19088 (PMID: $31823835)$

2. Sorrentino F, Gheller F, Favaretto N, Franz L, Stocco E, Brotto D, Bovo R (2020) Music perception in adult patients with cochlear implant. Hearing Balance Commun 18(1):3-7

3. Dritsakis G, van Besouw RM, Kitterick P, Verschuur CA (2017) A music-related quality of life measure to guide music rehabilitation for adult cochlear implant users. Am J Audiol 26(3):268-282. https://doi.org/10.1044/2017_AJA-16-0120 (PMID: 28614845)

4. Buyens W, van Dijk B, Wouters J, Moonen M (2015) A Stereo Music preprocessing scheme for cochlear implant users. IEEE Trans Biomed Eng 62(10):2434-2442. https://doi.org/10.1109/ TBME.2015.2428999 (Epub 2015 May 8 PMID: 25966469)

5. Di Nardo W, Scorpecci A, Giannantonio S, Cianfrone F, Paludetti G (2011) Improving melody recognition in cochlear implant recipients through individualized frequency map fitting. Eur Arch Otorhinolaryngol 268(1):27-39. https://doi.org/10.1007/s00405010-1335-7 (Epub 2010 Jul 16 PMID: 20635091)

6. Looi V, Gfeller K, Driscoll V (2012) Music appreciation and training for cochlear implant recipients: a review. Semin Hear 33(4):307-334. https://doi.org/10.1055/s-0032-1329222

7. Hwa TP, Wen CZ, Ruckenstein MJ (2021) Assessment of music experience after cochlear implantation: a review of current tools and their utilization. World J Otorhinolaryngol Head Neck Surg 7(2):116-125. https://doi.org/10.1016/j.wjorl.2021.02.003

8. Drennan WR, Oleson JJ, Gfeller K et al (2015) Clinical evaluation of music perception, appraisal and experience in cochlear implant users. Int J Audiol 54(2):114-123. https://doi.org/10. 3109/14992027.2014.948219

9. Brockmeier SJ, Nopp P, Vischer M, Baumgartner W, Stark $\mathrm{T}$, Schoen F et al (2002) Correlation of speech and music perception in postlingually deaf Combi 40/40+ users. In: Kubo T, Takahashi Y, Iwaki T (eds) Cochlear implants: an update. Kugler Publications, The Hague, pp 459-464

10. Looi V, She J (2010) Music perception of cochlear implant users: a questionnaire, and its implications for a music training program. Int J Audiol 49(2):116-128. https://doi.org/10.3109/ 14992020903405987 (PMID: 20151886)

11. Akbulut AA, Çiprut A, Akdeniz E, Batman Ç (2021) Translation and validation of the music-related quality of life questionnaire for adults with cochlear implant in Turkish language. Eur Arch Otorhinolaryngol. https://doi.org/10.1007/s00405-021-06693-w

12. Sousa VD, Rojjanasrirat W (2011) Translation, adaptation and validation of instruments or scales for use in cross-cultural health care research: a clear and user-friendly guideline. J Eval Clin Pract 17(2):268-274. https://doi.org/10.1111/j.1365-2753.2010.01434.x (Epub 2010 Sep 28 PMID: 20874835)

13. World Medical Association (2013) World Medical Association Declaration of Helsinki: ethical principles for medical research involving human subjects. JAMA 310(20):2191-2194. https://doi. org/10.1001/jama.2013.281053 (PMID: 24141714)

14. Revelle W (2019) psych: procedures for psychological, psychometric, and personality research. [R package]. Retrieved from https://cran.r-project.org/package $=$ psych

15. Harrington D (2009) Confirmatory factor analysis. Oxford University Press, New York, pp 21-35

16. The Jamovi Project (2021) Jamovi. (Version 1.6) [Computer Software]. Retrieved from https://www.jamovi.org

17. R Core Team (2020) R: A Language and environment for statistical computing. (Version 4.0) [Computer software]. Retrieved from https://cran.r-project.org. (R packages retrieved from MRAN snapshot 2020-08-24)

18. MacCallum RC, Browne MW, Sugawara HM (1996) Power analysis and determination of sample size for covariance structure modeling. Psychol Methods 1(2):130-149. https://doi.org/10. 1037/1082-989X.1.2.130

19. Torppa R, Huotilainen M (2019) Why and how music can be used to rehabilitate and develop speech and language skills in hearing-impaired children. Hear Res 1(380):108-122. https://doi. org/10.1016/j.heares.2019.06.003 (Epub 2019 Jun 25 PMID: 31265971)

20. McKay CM (2021) No evidence that music training benefits speech perception in hearing-impaired listeners: a systematic review. Trends Hear 25:2331216520985678. https://doi.org/10. $1177 / 2331216520985678$

Publisher's Note Springer Nature remains neutral with regard to jurisdictional claims in published maps and institutional affiliations. 